\title{
Comunicação
}

[Communication]

\section{Esporotricose experimental sistêmica em ratos Wistar: avaliação hematológica e perfil hepático}

[Systemic experimental sporotrichosis in Wistar rats: hematological evaluation and hepatic profile]

\author{
A.R.M. Meinerz ${ }^{1}$, T.A. Antunes $^{2}$, F.V. Silva ${ }^{2}$, M.O. Xavier $^{1}$, M.B. Cleff ${ }^{\text {, }}$, M.C.A. Meireles ${ }^{2}$ \\ ${ }^{1}$ Aluna de pós-graduação - UFRGS - Porto Alegra, RS \\ ${ }^{2}$ Departamento de Veterinária Preventiva - UFPel - Pelotas, RS
}

A esporotricose é uma micose subcutânea decorrente da infecção pelo fungo dimórfico Sporothrix schenckii. A enfermidade é cosmopolita, porém com maior ocorrência nas regiões tropicais e subtropicais (Lacaz et al., 2002). No Brasil, é a terceira micose subcutânea de maior freqüência, e a principal na Região Sul (Morris-Jones, 2002).

O homem e várias espécies de animais são suscetíveis ao $S$. schenckii, especialmente os felinos, sendo a forma linfocutânea da micose a mais freqüente (Lacaz et al., 2002). Nesta espécie, tal enfermidade pode afetar o estado geral ao animal e provocar a disseminação do agente a partir de um foco cutâneo inicial, devido, provavelmente, à imunossupressão ou ao estado de anergia específica ao fungo (LopesBezerra et al., 2006).

Para o tratamento da esporotricose em felinos, utiliza-se itraconazol nas doses de 10 a $40 \mathrm{mg} / \mathrm{kg}$, e, normalmente, há uma boa resposta à terapia antifúngica, sendo pouco freqüentes os efeitos tóxicos. No entanto, são comuns as recidivas, podendo ocorrer óbitos, especialmente nos animais com formas mais graves da micose (Schubach et al., 2004).

Considerando a importância do felino doméstico nos relatos zoonóticos da esporotricose, assim como a gravidade da micose nessa espécie, o objetivo do trabalho foi avaliar o perfil hepático,

Recebido em 19 de julho de 2007

Aceito em 4 de abril de 2008

Endereço para correspondência (corresponding address)

Rua Santa Cruz, 2530A - 96015-710 - Pelotas, RS

E-mail: rmeinerz@bol.com.br as proteínas plasmáticas totais (PPT) e o hemograma na esporotricose experimental sistêmica.

Neste estudo, foram utilizados 12 ratos Wistar machos, com oito semanas de idade. Os animais foram alojados no Biotério Central da Universidade Federal de Pelotas. $\mathrm{O}$ experimento foi realizado de acordo com as recomendações do Colégio Brasileiro de Experimentação Animal, com aprovação prévia do Comitê de Ética da UFPel. Os animais foram inoculados pela veia lateral da cauda e pela via intraperitonial com $0,1 \mathrm{ml}$ de suspensão fúngica contendo $2 \times 10^{3} \mathrm{UFC}$ de $S$. schenckii e foram acompanhados por 30 dias. Nesse período, apresentaram apatia, perda de peso e nódulos cutâneos acompanhados de crostas e úlceras.

$\mathrm{Na}$ necropsia, observaram-se lesões nodulares esbranquiçadas, localizadas e/ou disseminadas no fígado, baço, tecido subcutâneo e testículos (Fig. 1). Histologicamente, observou-se presença de células leveduriformes, alongadas, com brotamento unipolar, intra e intercelulares, compatíveis com S. schenckii (Morris-Jones, 2002; Lopes-Bezerra et al., 2006). O sangue coletado por punção-cardíaca foi encaminhado ao setor de patologia. As enzimas hepáticas foram analisadas usando-se de kit comercial específico $^{1}$, com posterior leitura em aparelho de espectrofotometria.

Os resultados da análise das enzimas alanina aminotransferase (ALT) e fosfatase alcalina (FA) são apresentados na Tab. 1. A elevação dos

${ }^{1}$ Labtest ${ }^{\circledR}$ 
índices da FA provavelmente ocorreu em conseqüência da disseminação do agente no parênquima hepático, uma vez que foram detectadas alterações macro e micromorfológicas no fígado. Estudos prévios em humanos com esporotricose não mostraram alterações relacionadas ao perfil hepático (García et al., 2004). Em animais domésticos, não há estudos que correlacionem alterações hepáticas com a esporotricose.

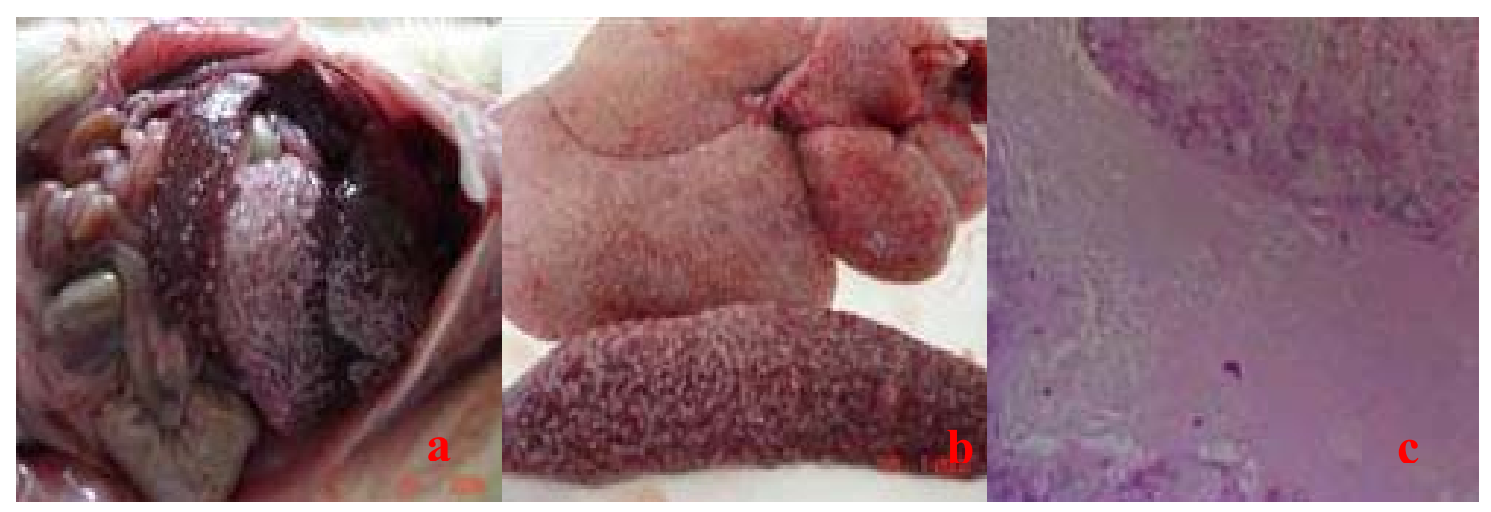

Figura 1. Esporotricose experimental sistêmica: lesões nodulares e esbranquiçadas disseminadas. a: baço; b: fígado; c: corte histológico de vaso sanguíneo hepático com células de Sporothrix schenckii (PAS400x).

Tabela 1. Valores da alanina aminotransferase (ALT) e fosfatase alcalina (FA) de ratos norvergicus Wistar com esporotricose sistêmica experimental

\begin{tabular}{ccc}
\hline Animais & ALT (UI/1) & FA (UI/l) \\
\hline 1 & 46,0 & 67,3 \\
2 & 37,0 & 248,7 \\
3 & 40,0 & 100,1 \\
4 & 35,0 & 117,1 \\
5 & 35,0 & 118,8 \\
6 & 39,0 & 193,5 \\
7 & 40,0 & 251,3 \\
8 & 53,0 & 168,1 \\
9 & 47,0 & 118,6 \\
10 & 47,0 & 205,6 \\
11 & 48,0 & 124,6 \\
12 & 47,0 & 191,6 \\
\hline
\end{tabular}

Em relação à patologia clínica, 66,7\% (8/12) dos animais apresentaram PPT elevadas $(7,9-8,5 \mathrm{~g} \%)$; $75 \%$ (9/12), redução do hematócrito, de hemoglobina e da contagem de hemácias; e 8,3\% (1/12), anemia mascarada por desidratação. As alterações hematológicas foram, provavelmente, decorrentes do quadro de prostração e inapetência comum na micose. A anemia em pacientes com esporotricose já foi descrita por outros autores (Caballero et al., 2000).

No leucograma, $50 \% \quad(6 / 12)$ apresentaram leucocitose por neutrofilia com desvio à esquerda regenerativo, 8,3\% (1/12) tinham neutrofilia e desvio à esquerda degenerativo e 33,3\% (4/12) apresentaram leucocitose devido à linfocitose. Estes achados confirmam o caráter infeccioso e o comprometimento sistêmico dos animais com esporotricose, já relatados por Morris-Jones (2002).

Os resultados permitem concluir que a esporotricose sistêmica provoca alterações hematológicas, anatomopatológicas e na FA, e que essas podem interferir no tratamento e no restabelecimento do animal ou agravar a enfermidade.

Palavras-chave: rato, esporotricose experimental, Sporotrix schenckii, enzimas hepáticas

\section{ABSTRACT}

Alanine aminotransferase (ALT) and alkaline phosphatase (AP) hepatic enzymes, hematological values, and total plasmatic proteins (TPP) of 12 Wistar rats with systemic experimental sporotrichosis were evaluated. Inoculation was performed at $2 \times 10^{3}$ cells of $\mathrm{S}$. schenckii $/ \mathrm{ml}$. The values ranged from 35 to 48UI/l for ALT and 67 to 251.3UI/l for AP. Fifty percent of the AP values were above the physiological 
limits. TPP was elevated in $66.7 \%$ (8/12) of the rats with values varying from 7.9 to $8.5 \mathrm{~g} \%$. In $75 \%(9 / 12)$ of the animals, it was observed that hemoglobin and red blood cells count were below the physiologic limits, and $8.3 \%(1 / 12)$ of the animals showed anemia masked by dehydration. At the necropsy, it was observed local and/or disseminated nodular lesions. At the histological analysis, cells compatible to S. schenckii were found. The observed alterations are aggravating factors for the recurrence and treatment of the mycosis.

Keywords: rat, experimental sporotrichosis, Sporothrix schenckii, hepatic enzymes

\section{REFERÊNCIAS BIBLIOGRÁFICAS}

CABALLERO, A.B.A.; MARTINEZ, J.C.; RIVELLI,V. et al. Esporotricosis en niños: Comunicación de tres casos con localización facial. Pediatria, v.27, p.32-36, 2000.

GARCÍA, R.; FIGUEROA, Y.; UGARTE, G. El caso más temprano de esporotricosis pediátrica en el Peru. Folia Dermatol. Peru., v.15, p.105107, 2004.

LACAZ, C.S.; PORTO, E.; MARTINS, J.E.C. et al. Tratado de micologia médica. 9.ed. São Paulo: Sarvier, 2002.
LOPES-BEZERRA, L.; SCHUBACH, A.; ROSANE-COSTA, O. Sporothrix schenckii and Sporotrichosis. An. Acad. Bras. Cien., v.78, p.293-308, 2006.

MORRIS-JONES. Sporotrichosis. Clin. Dermatol., v.27, p.427-431, 2002.

SCHUBACH, T.M.P.; SCHUBACH, A.O.; KAMOTO BARROS, T.M.B.L. et al. Evaluation of an epidemic of sporotrichosis in cats: 347 cases (1998-2001). J. Am. Vet. Med. Assoc., v.224, p.1623-1629, 2004. 